\title{
Correction to: FTIR-ATR analysis of the H-bond network of water in branched polyethyleneimine/TEMPO-oxidized cellulose nano-fiber xerogels
}

\author{
Giuseppe Paladini - Valentina Venuti - Vincenza Crupi - Domenico Majolino • \\ Andrea Fiorati · Carlo Punta
}

Published online: 10 September 2020

(C) Springer Nature B.V. 2020

Correction to:

\section{Cellulose}

https://doi.org/10.1007/s10570-020-03380-7

Co-author Andrea Fiorati's status as one of the two corresponding authors was not originally indicated on the published version. This Correction remedies that omission.

Publisher's Note Springer Nature remains neutral with regard to jurisdictional claims in published maps and institutional affiliations.

The original article can be found online at https:// doi.org/10.1007/s10570-020-03380-7.

G. Paladini · V. Venuti · D. Majolino

Department of Mathematical and Computer Sciences, Physical Sciences and Earth Sciences, University of Messina, Viale Ferdinando Stagno D'Alcontres 31, 98166 Messina, Italy

\section{Crupi $(\square)$}

Department of Chemical, Biological, Pharmaceutical and Environmental Sciences, University of Messina, Viale Ferdinando Stagno D'Alcontres 31, 98166 Messina, Italy e-mail: vcrupi@unime.it
A. Fiorati $(\bowtie) \cdot$ C. Punta
Department of Chemistry, INSTM Local Unit, Materials, and Chemical Engineering "G. Natta", Politecnico di Milano, Via Mancinelli 7, 20131 Milan, Italy
e-mail: andrea.fiorati@polimi.it
C. Punta
C. N. R. Istituto di Chimica del Riconoscimento
Molecolare (ICRM), Milan, Italy 